\title{
A new thermostable and organic solvent-tolerant lipase from Aneurinibacillus thermoaerophilus strain $\mathrm{HZ}$
}

\begin{abstract}
A thermostable and organic solvent-tolerant lipase produced by Aneurinibacillus thermoaerophilus strain HZ was purified and characterised. The lipase was purified to apparent homogeneity with two steps: anion exchange chromatography on Q-Sepharose and gel filtration on Sephadex-G75. A final specific activity of $43.5 \mathrm{U} / \mathrm{mg}$ was obtained with an overall recovery of $19.7 \%$ and 15.6 purification fold. The molecular mass of the HZ lipase was estimated to be $50 \mathrm{kDa}$. The optimum $\mathrm{pH}$ for the activity of the purified $\mathrm{HZ}$ lipase was 7.0. The stability showed a broad range of $\mathrm{pH}$ values between $\mathrm{pH} 4.0$ and 9.0 at $30^{\circ} \mathrm{C}$. The purified $\mathrm{HZ}$ lipase exhibited an optimum temperature of $65^{\circ} \mathrm{C}$ with a half-life of $3 \mathrm{~h}$ and 10 $\min$ at $65^{\circ} \mathrm{C}$. The activity of the purified $\mathrm{HZ}$ lipase was stimulated in the presence of $\mathrm{Ca} 2+$. Organic solvents such as dimethyl sulfoxide (DMSO), methanol, n-tetradecane and nhexadecane enhanced the lipase activity. Studies on the effect of oil showed that the lipase preferred natural oil, such as sunflower oil, over synthetic substrates.
\end{abstract}

Keyword: Aneurinibacillus thermoaerophilus strain HZ; Thermostable lipase; Organic solvent tolerant; Purification; Characterisation 